\title{
Estimating multimorbidity prevalence with the Canadian Chronic Disease Surveillance System
}

\author{
Allison Feely, BSc (1); Lisa M. Lix, PhD (2); Kim Reimer, BSc (3)
}

This article has been peer reviewed.

Tweet this article

\begin{abstract}
Introduction: The Public Health Agency of Canada's Canadian Chronic Disease Surveillance System (CCDSS) uses a validated, standardized methodology to estimate prevalence of individual chronic diseases, such as diabetes. Expansion of the CCDSS for surveillance of multimorbidity, the co-occurrence of two or more chronic diseases, could better inform health promotion and disease prevention. The objective of this study was to assess the feasibility of using the CCDSS to estimate multimorbidity prevalence.
\end{abstract}

Methods: We used administrative health data from seven provinces and three territories and five validated chronic conditions (i.e. cardiovascular disease, respiratory disease, mental illness, hypertension and diabetes) to estimate multimorbidity prevalence. We produced age-standardized (using Canada's 1991 population) and age-specific estimates for two multimorbidity definitions: (1) two or more conditions, and (2) three or more conditions from the five validated conditions, by sex, fiscal year and geography.

Results: Among Canadians aged 40 years and over in the fiscal year 2011/12, the prevalence of two or more and three or more chronic conditions was $26.5 \%$ and $10.2 \%$, respectively, which is comparable to other estimates based on administrative health data. The increase in multimorbidity prevalence with increasing age was similar across provinces. The difference in prevalence for males and females varied by province and territory. We observed substantial variation in estimates over time. Results were consistent for the two definitions of multimorbidity.

Conclusion: The CCDSS methodology can produce comparative estimates of multimorbidity prevalence across provinces and territories, but there are challenges in using it to estimate temporal trends. Further expansion of the CCDSS in the number and breadth of validated case definitions will improve the accuracy of multimorbidity surveillance for the Canadian population.

Keywords: chronic disease, surveillance, prevalence, CCDSS

\section{Introduction}

Multimorbidity, the co-existence of two or more chronic diseases where one is not necessarily more central than the others, ${ }^{1}$ is becoming increasingly common, particularly among older adults. ${ }^{2-7}$ Multimorbidity prevalence is expected to rise, in Canada as in other countries, due to an aging population and an increasing prevalence of such chronic diseases as diabetes and hypertension. ${ }^{8}$ Multimorbidity is an important issue for health care providers and policy makers to monitor because it has been linked with potentially negative health outcomes, including decreased health-related quality of life ${ }^{9}$ and increased health care utilization and costs. ${ }^{10,11}$

The Canadian Chronic Disease Surveillance System (CCDSS) is a collaborative effort

\section{Highlights}

- The Canadian Chronic Disease Surveillance System (CCDSS) uses a standardized methodology based on administrative data to estimate the prevalence of chronic conditions, such as diabetes, for provinces and territories. We examined the feasibility of using the CCDSS for surveillance of multimorbidity, commonly defined as the co-occurrence of two or more chronic conditions.

- The overall prevalence of multimorbidity using this definition was $26.5 \%$ in 2011/12, based on data for five conditions (cardiovascular disease, respiratory disease, mental illness, hypertension, diabetes) from seven provinces and three territories. Age-specific trends were similar across jurisdictions, but changes over time showed substantial variation.

- The CCDSS will be increasingly useful for national multimorbidity surveillance as more chronic disease case definitions are added.

between the Public Health Agency of Canada (PHAC) and provincial and territorial governments. The goal of the CCDSS is to produce accurate estimates of chronic disease prevalence and incidence for such conditions as diabetes and hypertension. This information can be used in a number of ways, such as for assessing the impact of chronic disease on the health care system. The CCDSS produces comparative data using a population-based methodology that has been validated and standardized 
across provinces and territories. Currently, however, the CCDSS focusses on individual chronic diseases; it has not yet been investigated for multimorbidity surveillance.

At present, there is limited populationbased information about multimorbidity in Canada. Roberts et al. ${ }^{7}$ used data from the Canadian Community Health Survey (CCHS) to estimate multimorbidity prevalence for a single year and demonstrate its association with determinants of health such as age and income. Kuwornu et al. ${ }^{12}$ used CCHS data to compare the prevalence and characteristics of multimorbidity in Canadian Aboriginal and non-Aboriginal Caucasian populations. However, no population-based studies have provided comparative estimates for all of Canada's provinces and territories. A few population-based studies have been conducted for individual provinces or territories, ${ }^{6,13,14}$ but only one ${ }^{6}$ of these has examined changes in multimorbidity over time, and none have examined variations across population subgroups. Given this background, the purpose of this study was to assess the feasibility of using the CCDSS to estimate multimorbidity prevalence across population groups defined by age, sex and geography, and over time.

\section{Methods}

\section{Data sources}

A total of 10 provinces and territories provided data for the analyses reported in this study: British Columbia (BC), Manitoba (MB), Ontario (ON), Quebec (QC), New Brunswick (NB), Nova Scotia (NS), Newfoundland and Labrador (NL), Yukon (YT), Northwest Territories (NT) and Nunavut (NU). These jurisdictions responded to the v2015 CCDSS data call as of April 2015. These provinces and territories represent about $86 \%$ of the entire Canadian population, including all of Canada's northern population. ${ }^{15}$

The administrative health databases we used to estimate multimorbidity prevalence included hospital records, physician billing claims and population registry files. Hospital records and physician billing claims provide information about diagnosed disease cases that are recorded with the International Classification of Diseases, Ninth Revision (ICD-9), ${ }^{16}$ International Classification of Diseases, Ninth Revision, Clinical Modification (ICD-9-CM) ${ }^{17}$ and International Statistical
Classification of Diseases and Related Health Problems, Tenth Revision, Canada (ICD-10-CA). ${ }^{18}$ Population registry files capture all residents of the provinces and territories with valid health insurance coverage, and also provide demographic information (i.e. age and sex). These three data sources can be anonymously linked via a resident's unique lifetime identifier (i.e. health insurance number).

\section{Definitions of selected chronic conditions}

Five chronic conditions were included in this study: (1) cardiovascular disease, which includes ischemic heart disease and heart failure; (2) respiratory disease, which includes asthma and chronic obstructive pulmonary disease (COPD); (3) mental illness, a CCDSS omnibus category (including ICD-9 290-319) that encompasses psychosis, neurotic disorders, personality disorders, other nonpsychotic mental disorders and mental retardation; (4) hypertension; and (5) diabetes. We chose these chronic conditions because validated case definitions had been developed by the CCDSs. ${ }^{19-25}$ Additional chronic conditions that are prevalent in adults aged 40 years and over, such as arthritis and osteoporosis, are included in other multimorbidity definitions, but did not have validated CCDSS case definitions at the time of this study. All of the selected chronic conditions have been included in previous research about the measurement of multimorbidity. ${ }^{26}$

The selected chronic conditions were defined using case rules (Table 1) applied to administrative data for fiscal years 1995/96 and onward (a fiscal year extends from April 1 to March 31); prevalence estimates were produced for 2001/02 and 2011/12. Each case rule, which was developed by a CCDSS working group, describes the number and types of diagnosis codes that must be recorded in an administrative database in a specified period of time for an individual to be classified as a disease case. Fiscal year 2011/12 was the most current year for which data was available at the time the call for data was distributed to the provinces and territories.

We evaluated two definitions of multimorbidity. The first was the most common definition, which is the co-occurrence of two or more $(2+)$ chronic conditions. The second definition was the co-occurrence of three or more $(3+)$ conditions. This definition has also been investigated in previous research.?

\section{Statistical analysis}

We estimated the prevalence of multimorbidity for people aged 40 years and over by sex, five-year age group, province and territory, definition and fiscal year. We selected 40 years as the minimum age because it represents the common lower age limit among the chronic disease case definitions included in this research. We calculated age-standardized, age-specific and crude prevalence rates for each province and territory, and for all 10 provinces and territories combined. The age-standardized rates were calculated using Canada's 1991 population as the standard population. We calculated crude prevalence rates by dividing the number of people with multimorbidity by the total population as defined by the provincial or territorial population registry. We conventionally rounded prevalence counts to adjacent multiples of five (rounded to multiples of 10 for Ontario and overall data).

We described the data in both tabular and graphic forms. Comparisons between jurisdictions over time and across population subgroups were conducted using percentages, ranks and the coefficient of variation, a statistical measure of dispersion. We produced $95 \%$ confidence intervals ( $95 \%$ CIs) for the estimates of the magnitude of the difference between subgroups using a large-sample chi-square $\left(\chi^{2}\right)$ distribution. We used the Spearman rank-order correlation to describe the association between the prevalence estimates obtained from the two multimorbidity definitions at the provincial/ territorial level because the distribution of the estimates could not be assumed to follow a normal distribution. The nonparametric Mantel-Haenszel statistic, which asymptotically follows a $\chi^{2}$ distribution, was used to test the linear trend over time. All statistical analyses were performed using SAS version $9.3 .^{27}$

\section{Results}

Table 2 reports the estimated age-standardized prevalence of multimorbidity by definition (i.e. $2+$ and $3+$ conditions) for each province and territory, and for the 10 provinces and territories overall, in the first and last years of the study period. In 2011/12, the overall age-standardized prevalence of $2+$ chronic conditions was 
TABLE 1

CCDSS case definitions for the chronic conditions selected to estimate multimorbidity prevalence

\begin{tabular}{|c|c|c|c|c|c|c|}
\hline \multirow[b]{2}{*}{ Chronic condition } & \multirow[b]{2}{*}{ Algorithm } & \multirow{2}{*}{$\begin{array}{l}\text { Age } \\
\text { range } \\
\text { (years) }\end{array}$} & \multirow[b]{2}{*}{ Case date } & \multicolumn{2}{|c|}{ Hospital \& physician codes } & \multirow[b]{2}{*}{ Exclusions } \\
\hline & & & & ICD-9-CM & ICD-10-CA & \\
\hline \multicolumn{7}{|l|}{ Cardiovascular } \\
\hline Ischemic heart disease & $\begin{array}{l}\text { One or more hospitalizations or two or } \\
\text { more physician codes within one year }\end{array}$ & $20+$ & $\begin{array}{l}\text { Hospital separation or } \\
\text { last physician visit } \\
\text { (whichever comes first) }\end{array}$ & $410-414$ & $120-125$ & None \\
\hline Heart failure & $\begin{array}{l}\text { One or more hospitalizations or two or } \\
\text { more physician codes within one year }\end{array}$ & $40+$ & $\begin{array}{l}\text { Hospital separation or } \\
\text { last physician visit } \\
\text { (whichever comes } \\
\text { first) }\end{array}$ & 428 & 150 & None \\
\hline \multicolumn{7}{|l|}{ Respiratory } \\
\hline Asthma & $\begin{array}{l}\text { One or more hospitalizations or two or } \\
\text { more physician claims within two years }\end{array}$ & $1+$ & $\begin{array}{l}\text { Hospital separation or } \\
\text { last physician visit } \\
\text { (whichever comes } \\
\text { first) }\end{array}$ & 493 & $\mathrm{~J} 45, \mathrm{~J} 46$ & None \\
\hline COPD & $\begin{array}{l}\text { One or more hospitalizations or one } \\
\text { or more physician claims }\end{array}$ & $35+$ & $\begin{array}{l}\text { Hospital separation or } \\
\text { last physician visit } \\
\text { (whichever comes } \\
\text { first) }\end{array}$ & 491, 492, 496 & $\mathrm{~J} 41-\mathrm{J} 44$ & None \\
\hline \multicolumn{7}{|l|}{ Mental illness } \\
\hline Omnibus & $\begin{array}{l}\text { One or more hospitalizations or one or } \\
\text { more physician claims within one year }\end{array}$ & $0+$ & $\begin{array}{l}\text { Hospital separation or } \\
\text { last physician visit } \\
\text { (whichever comes } \\
\text { first) }\end{array}$ & $290-319$ & F00-F99 & None \\
\hline \multicolumn{7}{|l|}{ Hypertension } \\
\hline & $\begin{array}{l}\text { One or more hospitalizations or two or } \\
\text { more physician claims within two } \\
\text { years }\end{array}$ & $20+$ & $\begin{array}{l}\text { Hospital separation or } \\
\text { last physician visit } \\
\text { (whichever comes } \\
\text { first) }\end{array}$ & $401-405$ & I10-I13, I15 & $\begin{array}{l}\text { Pregnancy- } \\
\text { induced } \\
\text { hypertension in } \\
\text { women aged } 20 \\
\text { to } 54 \text { years }\end{array}$ \\
\hline \multicolumn{7}{|l|}{ Diabetes } \\
\hline & $\begin{array}{l}\text { One or more hospitalizations or two or } \\
\text { more physician claims within two years }\end{array}$ & $1+$ & $\begin{array}{l}\text { Hospital separation or } \\
\text { last physician visit } \\
\text { (whichever comes } \\
\text { first) }\end{array}$ & 250 & E10-E14 & $\begin{array}{l}\text { Gestational } \\
\text { diabetes in } \\
\text { women aged } 10 \\
\text { to } 54 \text { years }\end{array}$ \\
\hline
\end{tabular}

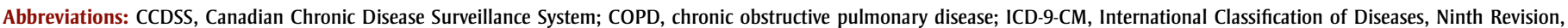
Clinical Modification; ICD-10-CA, International Statistical Classification of Diseases and Related Health Problems, Tenth Revision, Canada.

$26.5 \%$. This was a $29.3 \%$ relative increase over the $2001 / 02$ estimate of $20.5 \%$. The overall age-standardized prevalence of $3+$ chronic conditions was $10.2 \%$ in $2011 / 12$ which was a $50.0 \%$ increase over the $2001 / 02$ estimate of $6.8 \%$. The linear trend in the prevalence of $2+$ conditions was statistically significant $(p<.001)$; the same was true for $3+$ conditions $(p<.001)$. There was a strong association between the prevalence estimates obtained from the two multimorbidity definitions at the provincial/territorial level using the Spearman correlation coefficient; the estimated correlation was 0.94 in 2001/02 (data not shown).

For the multimorbidity definition of $2+$ chronic conditions, the lowest estimate across the provinces and territories was $6.5 \%$ (NU) in 2001/02 and $24.0 \%$ (NT) in $2011 / 12$. The highest estimate was $23.5 \%$ in $2001 / 02$ and $30.3 \%$ in $2011 / 12$, both from NS. For the multimorbidity definition of $3+$ conditions, the lowest estimate in $2001 / 02$ was $1.4 \%$ (NU) and in 2011/12 it was $9.1 \%$ (BC). The highest estimate in 2001/02 was $7.8 \%$ (NS) and in 2011/12 it was $12.0 \%(\mathrm{NU})$. The ranking of the provinces and territories in terms of the percentage increase between 2001/02 and 2011/12 was similar for both definitions of multimorbidity. NU showed the largest increase, at $326.2 \%$ for $2+$ conditions and $757.1 \%$ for $3+$ conditions between the two study years. The smallest increase was in NL: it was $24.9 \%$ for $2+$ chronic conditions and $39.7 \%$ for $3+$ chronic conditions.

Figure 1 shows the 2011/12 age-standardized prevalence of $2+$ chronic conditions by sex and province/territory. The overall prevalence was 1.1 percentage points (95\% CI: 1.1-1.2) higher for men than for women. Men had a higher prevalence than women in several of the provinces. However, prevalence was higher for women than men in all of the territories. The smallest absolute difference in estimated prevalence between men and women was observed for NL $(0.1 \%)$. The largest absolute difference was observed for NU $(3.8 \%)$. The overall prevalence of $3+$ diseases was 1.4 percentage points 
TABLE 2

Age-standardized multimorbidity prevalence ${ }^{\mathrm{a}}$ estimates (\%) and $95 \% \mathrm{Cls}$, stratified by multimorbidity definition and fiscal year

\begin{tabular}{|c|c|c|c|c|c|c|c|c|c|c|c|c|}
\hline \multirow{4}{*}{$\begin{array}{l}\begin{array}{c}\text { Province or } \\
\text { territory }\end{array} \\
\mathrm{BC}\end{array}$} & \multicolumn{12}{|c|}{ Multimorbidity definition (\# of chronic conditions) } \\
\hline & \multicolumn{6}{|c|}{$2+$ conditions } & \multicolumn{6}{|c|}{$3+$ conditions } \\
\hline & \multicolumn{2}{|c|}{$\begin{array}{c}2001 / 02 \\
\%(95 \% \mathrm{Cl})\end{array}$} & \multicolumn{2}{|c|}{$\begin{array}{c}2011 / 12 \\
\%(95 \% \mathrm{Cl})\end{array}$} & \multicolumn{2}{|c|}{$\%$ Increase (rank) } & \multicolumn{2}{|c|}{$\begin{array}{c}2001 / 02 \\
\%(95 \% \mathrm{Cl})\end{array}$} & \multicolumn{2}{|c|}{$\begin{array}{c}2011 / 12 \\
\%(95 \% \mathrm{Cl})\end{array}$} & \multicolumn{2}{|c|}{$\%$ Increase (rank) } \\
\hline & 17.4 & $(17.4-17.5)$ & 24.8 & $(24.8-24.9)$ & 42.5 & (3) & 5.2 & $(5.1-5.2)$ & 9.1 & $(9.1-9.2)$ & 75.0 & (3) \\
\hline MB & 20.4 & $(20.3-20.5)$ & 27.7 & $(27.6-27.8)$ & 35.8 & (5) & 6.4 & $(6.3-6.4)$ & 10.3 & $(10.3-10.4)$ & 60.9 & (5) \\
\hline NB & 19.6 & $(19.5-19.8)$ & 27.5 & $(27.4-27.7)$ & 40.3 & (4) & 6.5 & $(6.4-6.5)$ & 10.4 & $(10.3-10.5)$ & 60.0 & (6) \\
\hline NS & 23.5 & (23.4-23.6) & 30.3 & $(30.1-30.4)$ & 28.9 & (7) & 7.8 & (7.7-7.8) & 11.8 & (11.7-11.9) & 51.3 & (7) \\
\hline $\mathrm{NL}$ & 22.5 & (22.3-22.7) & 28.1 & (27.9-28.3) & 24.9 & (10) & 7.3 & $(7.2-7.5)$ & 10.2 & $(10.1-10.3)$ & 39.7 & (10) \\
\hline YT & 19.3 & (18.3-20.2) & 27.6 & $(26.8-28.5)$ & 43.0 & (2) & 6.1 & $(5.6-6.7)$ & 10.9 & $(10.4-11.5)$ & 78.7 & (2) \\
\hline
\end{tabular}

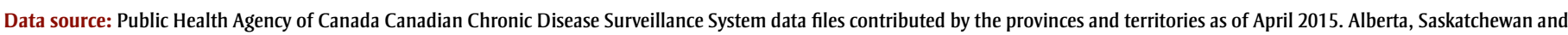
Prince Edward Island data were unavailable.

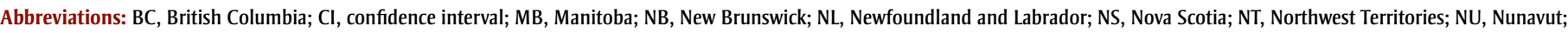
ON, Ontario; QC, Quebec; YT, Yukon.

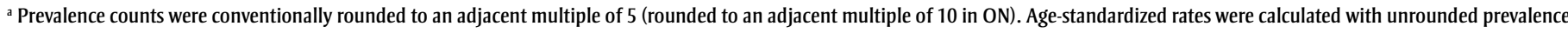
counts.

\section{FIGURE 1}

Age-standardized prevalence ${ }^{\mathrm{a}}(\%)$ of the co-occurrence of two or more chronic conditions among people aged 40 years and over, by sex and province/territory, 2011/12

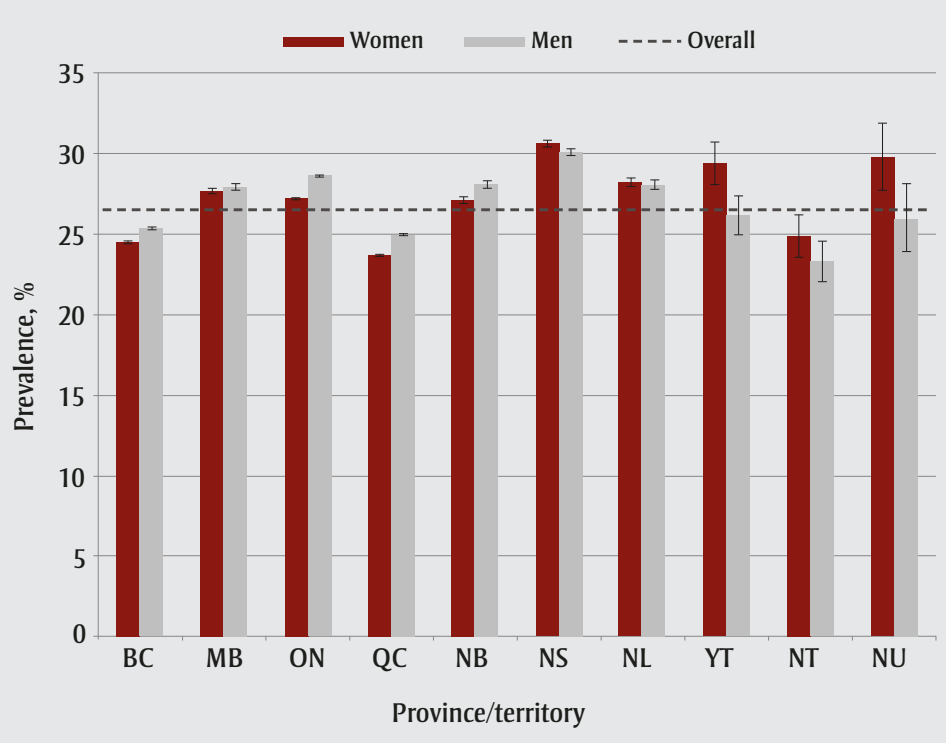

Data source: Public Health Agency of Canada, using Canadian Chronic Disease Surveillance System data files contributed by the provinces and territories as of April 2015. Alberta, Saskatchewan and Prince Edward Island data were unavailable.

Abbreviations: BC, British Columbia; MB, Manitoba; NB, New Brunswick; NL, Newfoundland and Labrador; NS, Nova Scotia; NT, Northwest Territories; NU, Nunavut; ON, Ontario; QC, Quebec; YT, Yukon.

Note: I signifies a $95 \%$ confidence interval.

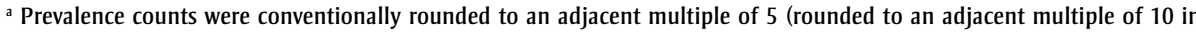
$\mathrm{ON})$. Age-standardized rates were calculated with unrounded prevalence counts.
(95\% CI: 1.3-1.4) higher for men than for women; prevalence was greater among men than women for all of the provinces, but was greater among women than men in all of the territories (data not shown).

The age-specific prevalence of the cooccurrence of $2+$ chronic conditions for each province and territory in 2011/12 is shown in Figure 2. The overall prevalence in the oldest age group ( $\geq 85$ years) was $66.3 \%$. This was $58.6 \%$ higher than the overall prevalence in the youngest age group (i.e. 40-44 years; $7.8 \%$ ). In 2001/02 (data not shown), the overall prevalence was $5.5 \%$ in the youngest age group and $52.1 \%$ in the oldest age group. In 2011/12, the overall prevalence of $3+$ conditions was $1.4 \%$ in the youngest age group and $35.6 \%$ in the oldest age group (data not shown).

The trend across age groups showed an S-shaped pattern for all provinces and territories. The coefficient of variation for the provinces and territories was similar in 2001/02 across age groups; it was 0.28 in the group aged 40 to 44 years and 0.27 in the group aged 85 years and over. In $2011 / 12$, the coefficient of variation was 0.24 in the youngest age group and just slightly lower, at 0.14 , in the oldest age 
FIGURE 2

Prevalence $^{\mathrm{a}}(\%)$ of the co-occurrence of two or more chronic conditions, by age group and province/territory, 2011/12

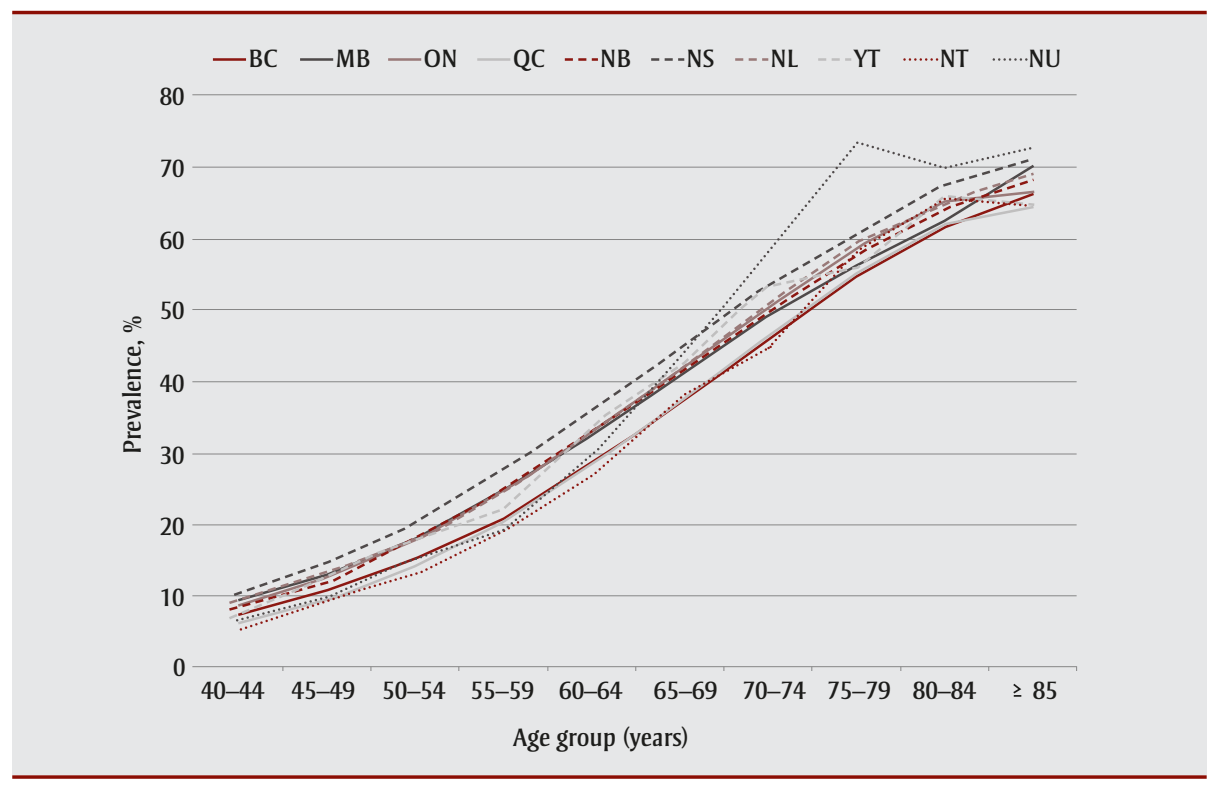

Data source: Public Health Agency of Canada, using Canadian Chronic Disease Surveillance System data files contributed by the provinces and territories as of April 2015. Alberta, Saskatchewan and Prince Edward Island data were unavailable.

Abbreviations: BC, British Columbia; MB, Manitoba; NB, New Brunswick; NL, Newfoundland and Labrador; NS, Nova Scotia; NT, Northwest Territories; NU, Nunavut; ON, Ontario; QC, Quebec; YT, Yukon.

a Prevalence counts were conventionally rounded to an adjacent multiple of 5 (rounded to an adjacent multiple of 10 in $\mathrm{ON}$ ). Age-standardized rates were calculated with unrounded prevalence counts.

group. A similar pattern was observed for $3+$ conditions, in that the coefficient of variation for 2011/12 was higher in the youngest age group (0.72) and lower in the oldest age group (0.30). In 2001/02, the coefficient of variation was 0.57 in the youngest age group and 0.20 in the oldest age group for $3+$ conditions.

\section{Discussion}

Of the population aged 40 years and over from the 10 provinces and territories that submitted study data to the CCDSS, about one-quarter had at least two of the five validated chronic conditions and about $10 \%$ had at least three of the five validated conditions for which CCDSS data were collected. Our overall estimate of $26.5 \%$ (for $2+$ conditions) in 2011/12 is lower than a recent study that estimated Canadian multimorbidity prevalence to be $42.6 \%$ for the population aged 18 years and older ${ }^{28}$ using national electronic medical record (EMR) data. Fortin et al. ${ }^{29}$ observed that multimorbidity prevalence estimates derived for primary care populations tend to be higher than for the general population. As well, that study used a list of 20 chronic conditions to identify patients with multimorbidity compared to the list of five chronic conditions used in our study. Using 2011/12 CCHS data, Roberts et al. ${ }^{7}$ estimated the national prevalence of $2+$ conditions to be $12.9 \%$, and the prevalence of $3+$ conditions to be $3.9 \%$; these estimates are substantially lower than ours and may reflect the impact of self-report bias on measurement of chronic diseases. ${ }^{30}$ The difference in estimates may also be partially explained by the difference in age groups studied; Roberts et al. ${ }^{7}$ included people aged 20 years and over, whereas we only estimated multimorbidity prevalence for people aged 40 years and over. A study from Ontario $^{6}$ that used administrative health data to estimate multimorbidity prevalence $(2+$ conditions $)$ reported a value of $24.3 \%$ in 2009 . However, the Ontario study included a broader range of chronic conditions (16 in total) than the ones included in the CCDSS study, and also included a broader range of ages ( 0 to 105 years).

Using CCDSS data, we observed no consistent pattern of differences between males and females across the jurisdictions. Previous research has also shown that the magnitude of the difference between males and females will reflect the choice of health conditions used to measure multimorbidity. ${ }^{31}$

We found that the age-standardized prevalence of multimorbidity increased substantially over time. To date, there have been no longitudinal studies of multimorbidity prevalence in Canada against which we might compare our findings. In fact, there have been few international studies that have focussed on longitudinal trends in multimorbidity prevalence. One exception is the study by Uijen and van de Lisdonk, ${ }^{32}$ which used electronic primary care data from the Netherlands and found that multimorbidity prevalence doubled over a 20-year period. Our results show increases between $25.2 \%$ and $78.7 \%$ in an 11-year period for all provinces and territories studied with the exception of Nunavut; further investigation is needed to determine why these increases have occurred. Wong et al. ${ }^{33}$ cautioned that there is the opportunity for an increased number of false positive cases to accrue over time, which may contribute to inflated rates of increasing prevalence across study years. For Nunavut, the large increases in prevalence may reflect the fact that Nunavut officially became a territory in 1999 and therefore its administrative databases may not have had time to sufficiently capture prevalent cases by $2001 / 02$. In other words, the first study year may be more likely to underestimate prevalence than in other provinces where administrative data from fiscal year 1995/96 onward were used for case ascertainment.

\section{Strengths and limitations}

The key strengths of this study are the use of the CCDSS's standardized and validated methodology, and the production of multimorbidity prevalence estimates for more than $80 \%$ of the Canadian population of adults aged 40 years and over. One limitation is that our study is based on validated case definitions for individual chronic conditions rather than an overall validated case definition for multimorbidity, and we were limited to five health conditions that were defined at the time of the provincial/ territorial call for data. Fortin et al. ${ }^{31}$ have suggested that limiting the conditions to fewer than seven chronic diseases may result in underestimation of the multimorbidity prevalence; these authors recommend including 12 or more chronic diseases. Diederichs et $\mathrm{al}^{34}$ identified 11 conditions that they recommend 
including in studies about multimorbidity. Diabetes, depression, hypertension, heart disease, and COPD are included in their list, as they were in our study. Additional conditions, such as arthritis, stroke, cancer and osteoporosis, which are found in other definitions, did not have validated CCDSS case definitions at the time of the call for data, but developmental work on case definitions for many of these conditions is underway or has been completed.

Table 3 summarizes the strengths and weaknesses of using the CCDSS to estimate multimorbidity. The CCDSS methodology facilitates comparisons across major determinants of health, including age, sex and region. These comparisons are useful for describing the absolute and relative impact of multimorbidity on different population groups, and can help target health promotion and disease prevention activities. However, the use of the CCDSS and administrative health data to measure multimorbidity presents some challenges. The methodology does not presently allow for comparisons across other important determinants of health, such as socioeconomic status. ${ }^{7,12,13}$ There is the potential for misclassification error in diagnoses recorded in administrative data, which can bias prevalence estimates. ${ }^{35,36}$ Administrative data do not capture individuals who have not had contact with the health care system for their chronic condition(s).

In addition, the finding that multimorbidity prevalence increased over time may be at least partially explained by changes in the quality and availability of administrative health data in the provinces and territories. Prevalence rates over time may also be influenced by the presence of individuals who have been incorrectly diagnosed with one or more chronic conditions. ${ }^{6}$ Furthermore, provinces and territories that have only a single diagnosis code in physician billing claims may underestimate multimorbidity prevalence, as there is a decreased probability for multiple diagnosis codes to be captured in these data. ${ }^{37}$ Finally, we should note that information about the severity of chronic conditions is not available in administrative data.

\section{Conclusion}

We applied validated methods for national surveillance of individual chronic diseases to provide comparative estimates of multimorbidity in selected provinces and territories over more than a decade. Our results showed several patterns that were consistent with previous research, including increases in multimorbidity over the

TABLE 3

Key strengths and weaknesses of using the CCDSS to estimate multimorbidity prevalence in Canada

\begin{tabular}{|c|c|}
\hline Strengths & Weaknesses \\
\hline $\begin{array}{l}\text { - The CCDSS uses standardized and validated } \\
\text { methodology in all provinces and territories } \\
\text { - The CCDSS uses routinely collected } \\
\text { administrative health data } \\
\text { - Using CCDSS data allows for comparisons } \\
\text { across age, sex, region and time } \\
\text { - Conducting research using administrative } \\
\text { health data is more economical than } \\
\text { engaging in primary data collection } \\
\text { - CCDS, } \\
\text { - CDS data is not influenced by recall bias }\end{array}$ & $\begin{array}{l}\text { The methodology does not currently allow } \\
\text { for comparisons across some determinants } \\
\text { of health, including socioeconomic status } \\
\text { and ethnicity } \\
\text { - There is the potential for misclassification } \\
\text { error in diagnoses recorded in administra- } \\
\text { tive health data }{ }^{34,35} \\
\text { CCDSS does not contain information on } \\
\text { laboratory results, which may reduce } \\
\text { misclassification errors, or chronic disease } \\
\text { lifestyle risk factors (i.e. physical activity, } \\
\text { smoking, etc.), which may in turn influence } \\
\text { multimorbidity risk }{ }^{36,40} \\
\text { CCDSS does not capture individuals who } \\
\text { have not received a diagnosis for the } \\
\text { chronic condition(s) under investigation } \\
\text { A limited number of validated chronic condi- } \\
\text { tions are currently included in the CCDSS } \\
\text { methodology }\end{array}$ \\
\hline
\end{tabular}

Abbreviation: CCDSS, Canadian Chronic Disease Surveillance System.

lifespan. ${ }^{2-7}$ While there was no consistent pattern across provinces and territories, higher rates tended to occur in eastern Canada than western Canada, which is not unexpected based on previous research..$^{38,39}$ Our findings suggest that the estimates have face validity. In terms of the increases in prevalence over time, there are few studies to which we can compare ours, and none based on Canadian data; trend estimates should be interpreted with caution.

We demonstrated the feasibility of using the CCDSS for individual chronic conditions to produce estimates of multimorbidity prevalence. However, its reach should be expanded with additional validated chronic disease case definitions to provide a more comprehensive profile of multimorbidity in Canada.

\section{Acknowledgements}

This study was made possible through collaboration between the Public Health Agency of Canada and the respective governments of British Columbia, Manitoba, Ontario, Quebec, New Brunswick, Nova Scotia, Newfoundland and Labrador, Yukon, Northwest Territories and Nunavut. The opinions, results and conclusions reported in this paper are those of the authors. No endorsement by the provinces and territories is intended or should be inferred.

Parts of this material are based on data and information compiled and provided by the Canadian Institute for Health Information (CIHI). However, the analyses, conclusions, opinions and statements expressed herein are those of the authors, and not necessarily those of CIHI.

We would also like to acknowledge the CCDSS Scientific Committee co-chairs and members for their input into this manuscript: Jay Onysko, Jean-François Godin, Michael Paterson, Chris Waters, Larry Svenson, Carla Ens, Nancy Yu, Kimberly Blinco, Maurice Collette, John Knight, Yalda Jarfari, Heather Hannah, Jill Casey, Michael A. Ruta, Angie Mullen, Sean Waites, Elsa Ho, Dr. Carol McClure, Valerie Emond, Marc Simard, Rolf Puchtinger, Shauna Démers, Marguerite Fenske, Mark Smith, Linda Van Til, Karen Tu and Joellyn Ellison.

\section{Conflicts of interest}

The authors declare no conflict of interest. 


\section{Authors' contributions}

AF contributed to the literature review, study design, statistical analyses and manuscript preparation. LL contributed to the study design, statistical analyses and manuscript preparation. KR contributed to the study design and manuscript preparation. All authors have read and approved the final manuscript.

\section{References}

1. Boyd CM, Fortin M. Future of multimorbidity research: how should understanding of multimorbidity inform health system design? Public Health Rev. 2010;32(2):451-74.

2. Barnett $K$, Mercer SW, Norbury $M$, Watt G, Wyke S, Guthrie B. Epidemiology of multimorbidity and implications for health care, research, and medical education: a cross-sectional study. Lancet. 2012;380:37-43.

3. van den Akker M, Buntinx F, Metsemakers JF, Roos S, Knottnerus JA. Multimorbidity in general practice: prevalence, incidence, and determinants of co-occurring chronic and recurrent diseases. J Clin Epidemiol. 1998;51(5):367-75.

4. Fortin M, Bravo G, Hudon C, Vanasse A, Lapointe L. Prevalence of multimorbidity among adults seen in family practice. Ann Fam Med. 2005; $3(3): 223-8$.

5. Rocca WA, Boyd CM, Grossardt BR, et al. Prevalence of multimorbidity in a geographically defined American population: patterns by age, sex, and race/ethnicity. Mayo Clin Proc [Internet]. 2014 [cited 2015 Jul 8];89(10):1336-49. Available from: http://dx.doi.org/10.1016/j.mayocp 2014.07.010

6. Koné Pefoyo AJ, Bronskill SE, Gruneir $A$, et al. The increasing burden and complexity of multimorbidity. BMC Public Health [Internet]. 2015 [cited 2015 Jul 27];15:415. Available from: http://dx.doi.org/10.1186/s 12889 $-015-1733-2$

7. Roberts KC, Rao DP, Bennett TL, Loukine L, Jayaraman GC. Prevalence and patterns of chronic disease multimorbidity and associated determinants in Canada. Health Promot Chronic Dis Prev Can. 2015;35(6): 87-94.
8. van den Akker M, Buntinx F, Roos S, Knottnerus JA. Problems in determining occurrence rates of multimorbidity. J Clin Epidemiol. 2001;54(7):675-9.

9. Fortin M, Bravo G, Hudon C, et al. Relationship between multimorbidity and health-related quality of life of patients in primary care. Qual Life Res. 2006;15(1):83-91.

10. Salisbury C, Johnson L, Purdy S, Valderas JM, Montgomery AA. Epidemiology and impact of multimorbidity in primary care: a retrospective cohort study. Br J Gen Pract. 2011;61(582):e12-e21.

11. Wolff JL, Starfield B, Anderson G. Prevalence, expenditures, and complications of multiple chronic conditions in the elderly. Arch Intern Med. 2002;162(20):2269-76.

12. Kuwornu JP, Lix LM, Shooshtari S. Multimorbidity disease clusters in Aboriginal and non-Aboriginal Caucasian populations in Canada. Chronic Dis Inj Can. 2014;34(4):218-25.

13. Agborsangaya CB, Lau D, Lahtinen M, Cooke T, Johnson JA. Multimorbidity prevalence and patterns across socioeconomic determinants: a crosssectional survey. BMC Public Health [Internet]. 2012 [cited 2015 Jul 27]; 12(1):201. Available from: http:// dx.doi.org/10.1186/1471-2458-12-201

14. St John PD, Tyas SL, Menec V, Tate R. Multimorbidity, disability, and mortality in community-dwelling older adults. Can Fam Physician. 2014;60(5): e272-e280.

15. Statistics Canada. Population and dwelling counts, for Canada, provinces and territories, 2011 and 2006 censuses [Internet]. 2015 [cited 2015 Jul 21]. Available from: http://www12 .statcan.gc.ca/census-recensement /2011/dp-pd/hlt-fst/pd-pl/Table -Tableau.cfm?LANG = Eng\&T $=101$ $\& S=50 \& O=A$

16. World Health Organization. International classification of diseases, ninth revision. Geneva (CH): WHO; 1977.

17. National Center for Health Statistics, Centers for Medicare and Medicaid Services. International classification of diseases, ninth revision: clinical modification (ICD $9 \mathrm{CM}$ ). Hyattsville (MD): National Center for Health Statistics; 1978.
18. Canadian Institute for Health Information. International statistical classification of diseases and related health problems, tenth revision. Ottawa (ON): Canadian Institute for Health Information; 2009. Available from: https://www.cihi.ca/en/icd_10 _ca_vol1_2009_en.pdf

19. Robitaille C, Bancej C, Dai S, et al. Surveillance of ischemic heart disease should include physician billing claims: population-based evidence from administrative health data across seven Canadian provinces. BMC Cardiovasc Disord [Internet]. 2013 [cited 2015 Aug 18];13:88. Available from: http://dx.doi.org/10.1186/1471 $-2261-13-88$

20. Blais C, Dai S, Waters C, et al. Assessing the burden of hospitalized and community-care heart failure in Canada. Can J Cardiol [Internet]. 2014 [cited 2015 Aug 18];30(3):352-8. Available from: http://dx.doi.org/10 .1016/j.cjca.2013.12.013

21. Gershon AS, Wang C, Guan J, Vasilevska-Ristovska J, Cicutto L, To T. Identifying patients with physician-diagnosed asthma in health administrative databases. Can Respir J [Internet]. 2009 [cited 2015 Jul 28];16(6):183-8. Available from: https://www.ncbi.nlm.nih.gov/pmc /articles/PMC2807792/

22. Gershon AS, Wang C, Guan J, Vasilevska-Ristovska J, Cicutto L, To T. Identifying individuals with physician diagnosed COPD in health administrative databases. COPD. 2009; 6(5):388-94.

23. Kisely S, Lin E, Lesage A, et al. Use of administrative data for the surveillance of mental disorders in 5 provinces. Can J Psychiatry. 2009;54(8): 571-5.

24. Quan H, Khan N, Hemmelgarn BR, et al. Validation of a case definition to define hypertension using administrative data. Hypertension. 2009;54(6): 1423-8.

25. Chen G, Khan N, Walker R, Quan H. Validating ICD coding algorithms for diabetes mellitus from administrative data. Diabetes Res Clin Pract [Internet]. 2010 [cited 2015 Jul 28];89(2):189-95. Available from: http://dx.doi.org/10 .1016/j.diabres.2010.03.007 
26. Britt HC, Harrison CM, Miller GC, Knox SA. Prevalence and patterns of multimorbidity in Australia. Med J Aust. 2008;189(2):72-7.

27. SAS Institute Inc. SAS/STAT 9.3 user's guide. Cary (NC): SAS Institute Inc.; 2011.

28. Nicholson K. Multimorbidity in Canada: examining prevalence and patterns using a national electronic medical record database. Paper presented at: Society for Academic Primary Care 45th annual scientific meeting; 2016 Jul 6-8; Dublin, Ireland.

29. Fortin M, Hudon C, Haggerty J, van den Akker M, Almirall J. Prevalence estimates of multimorbidity: a comparative study of two sources. BMC Health Serv Res [Internet]. 2010 [cited 2016 Aug 16];10(111):1-6. Available from: http://dx.doi.org/10.1186/1472 $-6963-10-111$

30. Gross R, Bentur N, Elhayany A, Sherf $\mathrm{M}$, Epstein L. The validity of self-reports on chronic disease: characteristics of underreporters and implications for the planning of services. Public Health Rev. 1996;24(2):167-82.

31. Fortin $M$, Stewart $M$, Poitras $M$, Almirall J, Maddocks H. A systematic review of prevalence studies on multimorbidity: toward a more uniform methodology. Ann Fam Med. 2012; 10(2):142-51.

32. Uijen AA, van de Lisdonk EH. Multimorbidity in primary care: prevalence and trend over the last 20 years. Eur J Gen Pract. 2008;14(Suppl 1):28-32.

33. Wong A, Boshuizen HC, Schellevis FG, Kommer GJ, Polder JJ. Longitudinal administrative data can be used to examine multimorbidity, provided false discoveries are controlled for. J Clin Epidemiol. 2011;64(10): 1109-17.

34. Diederichs C, Berger K, Bartels DB. The measurement of multiple chronic diseases-a systematic review on existing multimorbidity indices. J Gerontol A Biol Sci Med Sci. 2011; 66A(3):301-11.
35. Ladouceur M, Rahme E, Pineau CA, Joseph L. Robustness of prevalence estimates derived from misclassified data from administrative databases. Biometrics. 2007;63(1):272-9.

36. Virnig BA, McBean M. Administrative data for public health surveillance and planning. Annu Rev Public Health. 2001;22:213-30.

37. Lix LM, Walker R, Quan $\mathrm{H}$, et al. Features of physician services databases in Canada. Chronic Dis Inj Can. 2012;32(4):186-93.

38. Public Health Agency of Canada. Diabetes in Canada: facts and figures from a public health perspective. Ottawa (ON): Public Health Agency of Canada; 2012 [Catalogue No.: HP35-25/2011E].

39. Public Health Agency of Canada. Report from the Canadian Chronic Disease Surveillance System: hypertension in Canada, 2010. Ottawa (ON): Public Health Agency of Canada; 2010 [Catalogue No.: HP32-4/2010].

40. Blais C, Jean S, Sirois C, et al. Quebec Integrated Chronic Disease Surveillance System (QICDSS), an innovative approach. Chronic Dis Inj Can. 2014; 34(4):226-35. 